University of Nebraska - Lincoln

DigitalCommons@University of Nebraska - Lincoln

Power and the Creation of Patronizing Environments: The Stereotype-Based Behaviors of the Powerful and Their Effects on Female Performance in Masculine Domains

\author{
Theresa Vescio \\ Pennsylvania State University - Abington \\ Sarah J. Gervais \\ University of Nebraska-Lincoln, sgervais2@unl.edu \\ Mark Snyder \\ University of Minnesota \\ Ann Hoover \\ Pennsylvania State University
}

Follow this and additional works at: https://digitalcommons.unl.edu/psychfacpub

Part of the Psychiatry and Psychology Commons

\footnotetext{
Vescio, Theresa; Gervais, Sarah J.; Snyder, Mark; and Hoover, Ann, "Power and the Creation of Patronizing Environments: The Stereotype-Based Behaviors of the Powerful and Their Effects on Female Performance in Masculine Domains" (2005). Faculty Publications, Department of Psychology. 341.

https://digitalcommons.unl.edu/psychfacpub/341
}

This Article is brought to you for free and open access by the Psychology, Department of at DigitalCommons@University of Nebraska - Lincoln. It has been accepted for inclusion in Faculty Publications, Department of Psychology by an authorized administrator of DigitalCommons@University of Nebraska - Lincoln. 


\title{
Power and the Creation of Patronizing Environments: The Stereotype-Based Behaviors of the Powerful and Their Effects on Female Performance in Masculine Domains
}

\author{
Theresa K. Vescio, Department of Psychology, Pennsylvania State University \\ Sarah J. Gervais, Department of Psychology, Pennsylvania State University \\ Mark Snyder, Department of Psychology, University of Minnesota \\ Ann Hoover, Department of Psychology, Pennsylvania State University
}

\begin{abstract}
This work tested the following hypothesis: When powerful men stereotype their female subordinates in masculine domains, they behave in patronizing ways that affect the performance of their subordinates. Experiment 1 examined the stereotyping tendencies and patronizing behaviors of the powerful. Findings revealed that powerful men who stereotyped their female subordinates (i.e., those who were weakness focused) gave female subordinates few valued resources but much praise. In Experiment 2, low-power participants received resources (valued or devalued positions) and praise (high or low) from a powerful man. Subordinates who were assigned to a devalued position but received high praise (i.e., the patronizing behavior mirrored from Experiment 1) were angry. However, men performed better in the anger-inspiring situation, whereas women performed worse.
\end{abstract}

Keywords: power, stereotyping and discrimination, patronizing behavior, gender differences in performance, anger and performance

Social status and social group membership historically have been, and continue to be, confounded in most societies. Members of dominant social groups (e.g., men and European Americans in the United States) are more likely to hold highstatus positions of power than are members of negatively stereotyped groups (e.g., women and racial minorities). Therefore, dominant group members often hold positions that give authority to and legitimate their influence over members of negatively stereotyped groups (e.g., bosses, professors, administrators). In situations characterized by such power differentials, social psychological theorists have assumed that the stereotyping tendencies of powerful, dominant group members have meaningful and adverse consequences for low-power individuals who belong to negatively stereotyped groups. It has been suggested that stereotyping and power are linked in ways that reinforce boundaries between groups and maintain the status quo (Fiske, 1993; Jost \& Banaji, 1994; Pratto, Sidanius, Stallworth, \& Malle, 1994; Snyder \& Miene, 1994).

Additionally, several theorists have suggested that stable relations of social inequality (e.g., gender and race relations) are more effectively and typically maintained through the persuasive influences of paternalism rather than repeated acts of hostility and coercion (Jackman, 1994; Pratto \& Walker, 2001). Using gender as an example, powerful men often adopt an apparently benevolent responsibility for the welfare of subordi- nate women, like the traditional father does for his child (see also Glick \& Fiske, 1996, 2001). This sense of responsibility motivates positive sentiment toward women (e.g., nonthreatening and stereotypically nice women are perceived as wonderful; Eagly \& Mladinic, 1989; Fiske, Cuddy, Glick, \& Xu, 2002; Rudman \& Glick, 1999, 2001). The positive sentiment, in turn, masks social inequities, such that powerful men neither see women as equals (given their stereotypic incompetence) nor acknowledge discriminatory acts (Glick \& Fiske, 1996, 2001; Jackman, 1994). Women may detect that the positive regard of powerful men does not stem from respect, but they will comply with friendly but unfair overtures to avoid backlash (Glick \& Fiske, 2001; Rudman \& Glick, 1999, 2001) or social exclusion (Jackman, 1994). These dynamics presumably overlie interactions between powerful men and subordinate women in specific contexts (e.g., bosses and employees) as well as contribute to broad societal attitudes (e.g., benevolent sexism) and patronizingly positive acts (Glick \& Fiske, 2001; Jackman, 1994). Prior research has not, however, examined the way in which the patronizing acts of powerful men affect their low-power female recipients.

The present work examined the simultaneously inequitable and patronizingly positive ways in which powerful men behave toward the subordinate women whom they stereotype and the consequences that those behaviors have for their low-

\footnotetext{
Ann Hoover is now at the Department of Psychology, Purdue University; Sarah J. Gervais is now at the Department of Psychology, University of Nebraska-Lincoln.

This research was supported by a research award from the Research and Graduate Studies Office at Pennsylvania State University to Theresa K. Vescio. The authors thank Karen Gasper, Phil Goff, Cheryl Kaiser, Liz Pinel, and Landon Reid for comments on earlier versions of this article.

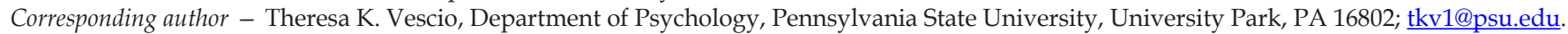


power recipients. To examine this broad issue and to derive testable hypotheses, we considered three questions: (a) What is patronizing behavior, (b) when do powerful people behave in patronizing ways toward their subordinates, and (c) what effects do patronizing behaviors have on low-power people?

\section{What Is Patronizing Behavior?}

We suggest that stereotyping processes operate differently across various judgments (Biernat \& Vescio, 2002) to produce a patronizing pattern of behavior that is marked by both groupbased inequities and trivial niceties. To explicate this suggestion, we distinguish between two kinds of behavior - the giving of valued resources versus verbal and nonverbal cues.

Judgments regarding the allocation of valued resources (e.g., raises, promotions) have a zero-sum character. Giving a raise to one, for instance, limits the funds remaining that can be distributed to others. As Biernat and Vescio (2002) noted, such zero-sum behaviors require a consideration of a set of actors and follow from comparisons across social categories. In a masculine domain, for instance, men and women are compared, and each individual's relative standing is assessed. When women are stereotyped (e.g., viewed as lacking valued masculine attributes, such as agency), they are perceived as having a lesser standing than men. Because valued resources are distributed to those with high standing, women receive fewer valued resources than do men.

Judgments about other behaviors have more of a non-zerosum character. Giving positive nonverbal cues and praise to one subordinate does not necessarily limit one's ability to respond similarly to others. Non-zero-sum behaviors, like praise, invoke a within-group judgment perspective. Women are compared with one's general expectations for women, and men are compared with one's expectations for men. In a masculine domain, a woman who exhibits basic counterstereotypic competencies (e.g., agency, athleticism) may surpass low stereotypebased expectations, and powerful people's judgments of and behavior toward her become more extreme in the direction of the expectancy violation (e.g., Jussim, Coleman, \& Lerch, 1987; Vescio \& Biernat, 1999). As a result, women who are surprisingly competent receive more praise and pats on the back than similarly competent but non-expectancy-violating men.

To the degree that powerful people allocate both valued resources and praise to their subordinates in a given context, adequately performing but negatively stereotyped subordinates should be the recipients of both discrimination in the allocation of valued resources and a great deal of concomitant praise. Although praise typically has a positive valence, it may take on a negative valence when paired with a lack of meaningful resources. As Foschi (1992) noted, such behaviors convey to their recipients that powerful and important others have judged them against a double standard rather than a fairly applied universal standard. As a result, in such situations, praise has a disingenuous and patronizing nature that can marginalize well-performing women.

The foregoing arguments provide an answer to the first question that guided our work - what is patronizing behavior? We suggest that patronizing behavior is a special instance of stereotype-based social inequity, whereby members of negatively stereotyped groups receive few valued resources but a great deal of seemingly disingenuous praise (Biernat \& Vescio,
2002; Biernat, Vescio, \& Manis, 1998). This answer is consistent with prior discussions of patronizing behavior, which noted that women's stereotypic lack of competence and/or agency may promote discrimination, whereas women's stereotypic communalism or niceness promotes patronizing niceties (e.g., Glick \& Fiske, 2001; Jackman, 1994; Rudman \& Glick, 1999, 2001). However, the present perspective additionally suggests that patronizing behavior may follow from the evaluation of women along a single stereotypic dimension (e.g., competence, agency, or athleticism) in different judgment contexts (those involving between-group comparisons vs. within-group comparisons). Consistent with this suggestion, findings have shown that participants who imagined themselves as the manager of a coed softball team estimated that they would assign fewer valued positions to women than men (e.g., short stop, batting cleanup) but praise women who hit a single more robustly than men who hit a single (Biernat \& Vescio, 2002).

Prior research has not, however, examined the conditions that promote patronizing behavior or the effects of that behavior on low-power people. We consider these issues in the present work. Because we suggest that patronizing behavior follows from stereotyping, we first consider the conditions in which the powerful stereotype their subordinates.

\section{When Do Powerful People Behave in Patronizing Ways Toward Their Subordinates?}

Our research has consistently shown that stereotyping tendencies of powerful people vary across situations and people. Whereas the socially meaningful groups to which low-power people belong may immediately grab the attention of powerful perceivers (e.g., gender of women and race of Blacks; Stroessner, 1996; Zarate \& Smith, 1990) and set the stage for category-based perception (Brewer, 1988; Fiske \& Neuberg, 1990), powerful people's tendency to categorize and subsequently stereotype women and racial minorities varies as a function of three factors.

First, powerful people stereotype low-power people when the stereotypes of the groups to which low-power people belong provide information that is contextually relevant. Cultural stereotypes contain information about a group's relative social status and explanations for that status (Eagly \& Karau, 2002; Wittenbrink, Gist, \& Hilton, 1997; Vescio \& Biernat, 1999). Because stereotypes explain social reality, they are relevant to a wide array of achievement domains. Stereotypes do not, however, provide information that facilitates the interpretation and elaboration of judgments on stereotype-irrelevant dimensions. Powerful men, for instance, exhibited antifemale biases in task allocation when success in a domain was associated with stereotypically masculine attributes (e.g., competitiveness) but not when success was associated with stereotype-irrelevant attributes (e.g., introversion-extraversion; Vescio, Gervais, \& Woodward, 2005).

Second, the stereotyping tendencies of powerful people vary, across and within groups, as a function of the degree to which people endorse the cultural stereotypes of the groups to which low-power people belong. For instance, men and women differ in their endorsement of sexist ideologies and stereotypes. Men more strongly endorse both hostile and benevolent sexist attitudes (Glick \& Fiske, 2001), view women as possessing fewer agentic traits (Diekman \& Eagly, 2000; 
Spence \& Buckner, 2000), and have less complex representations of women (Park \& Judd, 1990) than do women. Findings from the prejudice literature additionally show that those who endorse stereotypes (e.g., high prejudice) have stronger links between the content of stereotypic representations and category labels (Lepore \& Brown, 1997) and are less motivated to temper prejudiced responding (Plant \& Devine, 1998; Gaertner \& Dovidio, 1986) than people who reject stereotypes (e.g., low prejudice). Together, these findings suggest that those who endorse (vs. reject) negative stereotypes should more readily and frequently use stereotypes to make judgments about women and racial minorities. Consistent with this suggestion, findings show that powerful men (but not women) stereotype lowpower women in masculine domains (Vescio, Snyder, \& Butz, 2003), and powerful Whites who are high (but not low) in prejudice stereotype low-power Blacks in academic domains (Vescio, Heidenreich, \& Snyder, 2005).

Third, the contextually relevant stereotyping tendencies of powerful people who endorse stereotypes (e.g., powerful men and high-prejudice Whites) vary as a function of their social influence strategies, or plans about how to achieve subordinate-related goals (Vescio et al., 2003; Vescio, Heidenreich, \& Snyder, 2005). Vescio et al. (2003) demonstrated that powerful people initiate interactions with subordinates on the basis of social influence strategies, which can be manipulated across situations to take one of two forms that are differentially associated with stereotyping.

Weakness-focused social influence strategies are based on beliefs about how subordinates may impede goal striving. As such, they are associated with a heightened attention to contextually relevant weaknesses in subordinates and efforts to avoid subordinate-related impediments to goal strivings. In masculine and race-relevant domains, stereotypes of women and Blacks match weakness-focused social influence strategies. Stereotypes provide information about how women and Blacks may impede goal strivings (e.g., women are illogical and weak; Blacks are unintelligent and unmotivated). As a result, stereotyping should ensue.

In contrast, strength-focused social influence strategies are beliefs about how subordinates may enhance goal strivings. As a result, they are characterized by a heightened attention to the contextually relevant strengths in subordinates and efforts to enhance subordinate-related goal strivings. In this case, and in a masculine or race-relevant context, stereotypes are mismatched with social influence strategies. Stereotypes describe the strengths of women and Blacks (e.g., women are nurturing, Blacks are athletic), but those strengths are contextually irrelevant. Reliance on stereotypes in this situation would not provide information about how subordinates could enhance goal strivings. Therefore, stereotyping should not ensue.

The foregoing considerations of contextual relevance, stereotype endorsement, and social influence strategies provide the basis of the Social Influence Strategy $\times$ Stereotype Match hypothesis. This hypothesis predicts that powerful people will stereotype their subordinates when the stereotypes of the groups to which low-power people belong are contextually relevant, endorsed, and match social influence strategies. Consistent with this suggestion, findings show that powerful men (in masculine domains) and high-prejudice Whites (in academic domains) stereotype low-power women and Blacks when weakness focused but not strength focused (Vescio et al., 2003; Vescio, Heidenreich, \& Snyder, 2005). In the same stereotype-relevant contexts, however, powerful women and low-prejudice Whites do not stereotype their subordinates regardless of the social influence strategy they are encouraged to adopt.

If patronizing behavior follows from stereotyping, then powerful men who are weakness focused in a masculine domain should behave in patronizing ways toward subordinate women (give them fewer resources but more praise), whereas powerful men who are strength focused and powerful women (regardless of social influence strategy) should not. This suggestion provides an answer to the question of when the powerful behave in patronizing ways and represents the first hypothesis that the present research was designed to examine.

\section{What Effects Do Patronizing Behaviors Have on Low-Power People?}

Patronizing behavior has a contradictory duality. The output that stereotyped subordinates receive (few valued resources) does not logically and fairly follow from their input, which was praiseworthy. As noted at the outset, it has also been suggested that the duplicitous and unfair nature of patronizing behavior may go unnoticed by high-power actors (e.g., praise conceals discrimination in resource allocation) but be keenly apparent to the low-power and/or low social status people who are the recipients of such behavior (e.g., Jackman, 1994).

It is important to note that perceptions of injustices are related to anger (see Miller, 2001). For instance, when people were asked to recall instances in which they received unfair treatment and report the emotions they experienced, anger was the most frequently reported emotion (Clayton, 1992; Hassenbrauck, 1986; Mikula, 1986), which is an effect that has been replicated cross-culturally (Mikula, Scherer, \& Athenstaedt, 1998). Complementing these findings, examinations of anger in the workplace have revealed that anger among subordinates was most frequently related to perceptions of unfair treatment (Fitness, 2000). Anger is also one of the most common emotions that members of low-power, low social status groups report having had in response to group-based inequities (Bullock \& Houston, 1987; Steffen, McNeilly, Anderson, \& Sherwood, 2003; Swim, Hyers, Cohen, \& Ferguson, 2001; Swim, Hyers, Cohen, Fitzgerald, \& Bylsma, 2003).

Because patronizing behavior follows from negative stereotyping, women and Blacks should be the recipients of patronizing behavior more often than White men. However, because people who are low in situational power carefully process information about powerful others (Fiske, 1993, 2001; Keltner, Gruenfeld, \& Anderson, 2003), the duplicity of patronizing acts should be apparent to and arouse anger among all lowpower recipients - both infrequently patronized men and often patronized women. This suggestion is consistent with findings showing that (a) women experience anger in response to condescending treatment (Frodi, 1978), and (b) men and women report anger experiences of similar intensity and frequency (e.g., Fischer, Rodriguez Mosquera, van Vianen, \& Manstead, 2004; Kopper \& Epperson, 1991; Thomas, 1989).

Despite the fact that both men and women experience anger as their primary emotional response to perceptions of injustice, there are gender differences in the behavioral expres- 
sion of anger (see Shields, 2002). In contexts where women are low in social status and power, women are less likely than men to exhibit anger-inspired action intended to confront and fix an aversive situation (e.g., Fischer et al., 2004; Kopper \& Epperson, 1996). These gender differences can be understood given a consideration of the nature and function of anger.

Anger is associated with the behavioral approach system (e.g., Coan, Allen, \& Harmon-Jones, 2001; Harmon-Jones \& Sigelman, 2001), which is the motivational system posited to manage appetitive, incentive motivation and approach behavior (Gray, 1982, 1987; see also Cacioppo \& Bernston, 1994; Davidson, 1998; Depue \& Iacono, 1989). As a result, anger is a motivation aroused to assist in actions that rectify anger-arousing situations and facilitate approach behaviors. As Stein and Levine (1990, p. 65) have noted, however, anger-inspired action involves both the experience of an aversive state and the refusal of that state or the belief that one can act to ameliorate an anger-inspiring situation. Supporting this suggestion, recent findings have shown that anger is related to the behavioral approach system and inspires action only when people perceive the availability of acts that could alter the situation (Harmon-Jones, Sigelman, Bohlig, \& Harmon-Jones, 2003). When one fails to detect actions that could alter an adverse situation, feelings of anger persist while one remains in the adverse situation, but anger is unrelated to the behavioral approach system and reparative actions are not initiated.

The foregoing considerations suggest that men and women similarly experience anger in response to an aversive situation but differ in the degree to which they perceive that their actions may effectively alter an aversive situation (Shields, 2002). In stereotype-relevant achievement domains, this suggestion has performance implications. When low-power people are patronized, anger should be the primary emotion aroused and inspire performance strivings if (but only if) effort is perceived as being linked to task success and the elimination of the anger-inspiring (e.g., patronizing) situation. When one's personal performance is perceived as being unrelated to attempts to alter an aversive (and patronizing) situation, however, performance strivings should not be aroused. It is important to note that if performance strivings (or effort) are related to task success (as in the present research), and men and women differentially perceive that their performance strivings may alter an aversive situation, then gender differences in performance should emerge.

Therefore, in a masculine domain, we predict that lowpower men who are patronized should perform better, whereas low-power women who are patronized should perform worse. As noted, this prediction is based on the assumption that men and women differ in their perceptions of the degree to which their performance strivings are related to the amelioration of an aversive (patronizing) situation. Supporting this assumption, findings show that in masculine domains, women have lower expectations, are less confident, perceive less personal control, and perform less well than men (Meece, Parsons, Kaczala, \& Goff, 1982; Parsons, Kaczala, \& Meece, 1982; Ryckman \& Peckham, 1987; Stipek, 1984). Additionally, members of low-power, low social status groups (e.g., women and Blacks) are more attentive to the subtle instances of discrimination than are members of high-power, high social status groups (e.g., White men; Dovidio, Gaertner, Kawakami, \& Hodson, 2002; Dovidio, Kawakami, \& Gaertner, 2002; Vorauer \& Kumhyr, 2001). When discrimination is detected, percep- tions of personal control may be reduced such that members of low-status groups may be less likely to identify actions that could ameliorate the patronizing and anger-inspiring situation. As a result, group-based inequities may be associated with performance decrements among low-status but not highstatus group members (Schmader, Major, \& Gramzow, 2001).

\section{Overview of the Present Research}

The foregoing considerations provide the basis for three hypotheses. First, we predicted that weakness-focused men would categorize targets more strongly according to gender and behave in more patronizing ways toward subordinate women than would strength-focused men or women. Second, we predicted that anger would be the primary emotion aroused among low-power people who were treated in patronizing ways (men and women). Third, we predicted that low-power men would perform better when treated in patronizing ways and angered, whereas low-power women would perform worse.

To test the predictions of the first hypothesis, participants in Experiment 1 were assigned to high-power (team leader) roles, and social influence strategy was manipulated (strength or weakness). After reading background information about four female and four male subordinates, participants rated the similarity of each pair of targets, which provided a measure of categorization (e.g., same-gender versus cross-gender similarity). Participants also provided e-mail feedback to subordinates and assigned positions to subordinates (valued or devalued), which provided measures of praise and resource allocation, respectively.

Experiment 2 examined the consequences of the stereotype-based patronizing acts of powerful people for their lowpower recipients and tested the predictions of the second and third hypotheses. All participants were low-power team members who received position assignments (valued or devalued) and praise (high or low) from powerful others in ways paralleling the behaviors of participants in Experiment 1. Expectations for success in the domain were assessed following the introduction of the masculine context but prior to the receipt of feedback and role assignment. Following the receipt of feedback and position assignment, participants' mood and performance were assessed.

\section{Experiment 1}

\section{Method}

Participants

Participants were 182 Pennsylvania State University undergraduates. Participants were randomly assigned to social influence strategy condition (strength or weakness) and completed the experiment in return for credit in an introductory course. Five female and 6 male participants, who were equally distributed across social influence strategy conditions, expressed suspicion during debriefing. The responses of these 11 participants were omitted, leaving a working data set made up of the responses of 171 participants (100 women and $71 \mathrm{men}$ ).

\section{Design and Procedure}

After signing the informed consent statement, participants were led to believe that they would be participating in a study of leadership style and team functioning. Participants were told that students 
in two adjoining rooms were participating in the same experiment by means of networked computers. Participants were further led to believe that they would be working along with others as a team in an academic challenge against participants in sessions at other times. The academic challenge was described in stereotypically masculine terms (e.g., requiring strong strategic planning and competitive skills; these attributes were identified as masculine by an independent sample of 48 participants; for details, see Vescio et al., 2003). Participants also learned that a leader would be selected on the basis of the results from a leadership questionnaire, that leaders would provide feedback and communicate information about team selection and role assignment to team members, and that monetary rewards would be given to members of those teams that advanced through the first two rounds of the academic challenge. It is important to note that those assigned to different positions had the potential for differential rewards: $\$ 50$ to team leaders, $\$ 30$ to team captains, $\$ 20$ to those playing critical rounds, and no rewards to nonplaying team members. In reality, on completion of the experiment, $\$ 50$ prizes were given to 2 participants on the basis of a random drawing.

To strengthen the apparent masculinity of the context, participants were given $5 \mathrm{~min}$ to acquaint themselves with the kinds of problems involved in the challenge task. During this time, participants perused a binder containing problems created from quantitative and analytic Scholastic Achievement Test and Graduate Record Examination problems. Each problem was adapted to a stereotypically masculine context (e.g., appeared as a football problem) and presented with photographs (e.g., diagrammed plays and photos of players) to heighten the stereotypic masculinity of the problem.

After looking at a sample of the challenge tasks, participants began the computer task. The first portion of the computer program presented a bogus leadership questionnaire. While the questionnaire scores were presumably being tabulated, participants were asked to indicate their greatest academic strength and weakness. These were used to corroborate the cover story and to account for the fact that leaders later read similar information about each potential team member. All participants then learned that they were chosen to be team leader and were provided with leadership instructions, which included the manipulation of social influence strategy.

Manipulation of social influence strategy. Participants were given one of two sets of leadership instructions. In the weakness-focused condition, participants were told that the most successful leaders are those who are skilled in their ability to identify the weaknesses that others bring to work contexts. As a result, they are the kind of leaders who are able to minimize the likelihood that errors will be made on valued tasks. In contrast, participants in the strength-focused condition read that the best leaders are those who are skilled in their ability to identify the strengths of others. As a result, they are the kind of leaders who are able to maximize the likelihood that valued tasks will be completed successfully.

The final portion of the leadership instructions reminded participants of their potential to earn $\$ 50$ and highlighted that rewards to subordinate team members depended on the positions to which they were assigned by the leader. Noncaptain team members who competed in a round had the potential to earn $\$ 20$ and captains had the potential to earn $\$ 30$, whereas noncompeting team members and targets omitted from the team had no potential to earn money.

The computer "interaction" then commenced. First, participants selected an icon (from an array of cartoonlike depictions of male and female heads) and typed in a user ID. Participants believed that these personal identifiers would be attached to all correspondence with team members. Participants were then presented with 16 sentences describing their potential team members. Sentences were randomly paired with male and female icons. This information was presented to convey that each target possessed basic academic strengths required to complete the tasks and noncritical shortcomings, as well as being intended to give participants the sense that they had an informational basis on which to make team selections and position assignments. The first 8 sentences described academic strengths (e.g., "hardworking," "detail oriented"). The next 8 sentences described weaknesses (e.g., "procrastinator," "unorganized"). Sentences within each set of 8 were presented in random order.

Team selection and position assignment. After reading the background information, participants saw a screen containing the icons and user IDs of the eight targets (four female and four male). Participants selected five of the eight targets to be on their team (by clicking on the appropriate icons). The next screen presented the five individuals selected as team members. Participants chose three team members to play the first round; the other two team members were alternates who would complete the problems to try to earn an opportunity for play in later rounds, but those solutions were not considered as part of the team product. Finally, participants considered the three team members chosen to play the first round and identified a team captain.

After selecting a team, e-mail messages were constructed to the three players not selected for the team. Then, after selecting firstround players, e-mail messages were constructed to the two targets removed from competition (i.e., the alternates). Finally, e-mail messages were constructed for the remaining three targets following the selection of captain. E-mail messages were constructed under the guise that participants had to communicate their decisions and provide feedback to each of the potential team members. Therefore, one e-mail message was constructed for each of the eight targets.

E-mail correspondence. To facilitate the generation of e-mail messages, participants were presented with sentence stems. For each sentence stem, participants were asked to consider six response options that could be used to complete the sentence and to pick the response that best characterized what they would like to communicate to targets. The response options varied in praise (coded from 6 for the most praise to 1 for the least praise). The first three sentences were the same across e-mails and were used as a means of assessing praise. The common sentence stems included (a) "Your answers during the first phase of the experiment were ..." (sentence-completion options: "excellent," "very good," "good," "rather poor," "poor," "unsatisfactory"), (b) "Your answers were also ..." ("extremely informative," "very informative," "pretty informative," "rather uninformative," "very uninformative," and "extremely uninformative"), and (c) "If you were on the team you ..." ("would definitely make a contribution," "would probably make a contribution," "might make a contribution," "might not make a contribution," "probably would not make a contribution," "definitely would not make a contribution").

After all other judgments were made, participants considered each possible pair of targets (each female-female, male-male, and male-female pair) and rated the similarity of the two targets. These paired similarity ratings provided a measure of categorization strength.

\section{Dependent Variables}

Categorization. Categorization leads to the accentuation of similarities within groups (e.g., women similar to other women and men to other men) and differences between groups (e.g., men and women different from one another; Allport, 1954; Tajfel, 1959). If participants categorize subordinates on the basis of gender, then same-gender pairs of targets should be seen as more similar than opposite-gender pairs. Consistent with this idea, we created two measures to assess categorization strength. The same-gender perceived similarity index equaled the average similarity ratings of same-sex pairs (female-female and male-male). The opposite-gender similarity index equaled the average similarity ratings of opposite-sex pairs (male-female pairs).

Female position assignment. We first assigned points to each target corresponding to the value of the position assigned to that target using the following scheme: (a) 0 points to targets off the team, (b) 1 point to each of two targets on the team but assigned to the nonplaying alternate role, (c) 2 points to each of two targets selected as noncaptain players, and (d) 3 points to the target selected as captain. Because each participant chose one captain ( 3 points), two first-round players ( 2 points each), and two nonplaying first-round alternates (1 point each), there were 9 position-assignment points to be distributed 
Table 1. Categorization as Measured by Paired Similarity Judgments as a Function of Participant Gender and as a Function of Social Influence Strategy, Experiment 1

\begin{tabular}{lccc}
\hline & \multicolumn{2}{c}{ Perceived similarity } & \\
\cline { 2 - 3 } Variable & Same-gender pairs & Opposite-gender pairs & Difference: Same-opposite \\
\hline Participant gender & $4.58_{\mathrm{a}}$ & $4.07_{\mathrm{b}}$ & .51 \\
$\quad$ Men & $4.45_{\mathrm{a}}$ & $4.15_{\mathrm{b}}$ & .29 \\
$\quad$ & & .47 \\
Women & & $4.07_{\mathrm{b}}$ & .27 \\
Social influence strategy & $4.55_{\mathrm{a}}$ & $4.18_{\mathrm{b}}$ & \\
$\quad$ Weakness focused & $4.45_{\mathrm{a}}$ & & .27 \\
\hline
\end{tabular}

Note. For each effect, within rows and columns, means with different subscripts significantly differ at $p<.05$.

across the four female and four male targets. We created a female position-assignment variable by summing across the position points of the four female targets. Higher numbers on this variable reflect more valued position assignments. Male position-assignment variables could be similarly derived, but that variable is the inverse of (and not independent of) the female position-assignment variable and therefore not necessary. ${ }^{1}$

Praise. Praise scores were created for each target by considering the e-mail message written to that target and summing across the responses selected for each of the first three sentence stems, which were common across all e-mails. We then averaged across the target praise scores of the four female targets to create a female praise variable. We similarly derived a male praise variable. Higher numbers on these variables reflect greater praise.

\section{Results}

Weakness-focused men were expected to categorize targets more strongly according to gender and assign fewer valued positions to women than were strength-focused men or women. At the same time, however, weakness-focused men were expected to praise women more. To test these predictions, dependent variables (categorization, position assignment, and praise) were submitted to Social Influence Strategy (strength or weakness) $\times$ Participant Gender (male or female) analyses of variance (ANOVAs). When significant interactions emerged, we interpreted them by using simple effects tests that examined the effect of one variable (e.g., social influence strategy) within levels of the second variable (e.g., gender) and using Bonferroni corrections controlling for the familywise error rate (Maxwell \& Delaney, 1990).

\section{Categorization}

The categorization variables (same-gender and oppositegender similarity) were submitted to a mixed-model ANOVA. Type of similarity judgment (same or opposite gender) was a within-participants factor in this analysis. Participant gender and social influence strategy were between-participants variables. Three significant effects emerged from this analysis. A type of similarity judgment main effect, $F(1,167)=52.88, p$ $<.0001, \eta_{\mathrm{p}}{ }^{2}=.24$, revealed overall gender categorization. Samegender subordinates were perceived as being more similar $(M$ $=4.51)$ than opposite-gender subordinates $(M=4.12)$. This effect was, however, qualified by two interactions.
First, type of similarity judgment interacted with participant gender, $F(1,167)=4.53, p<.035, \eta_{p}^{2}=.03$. As the top of Table 1 shows, both male and female participants perceived same-gender targets as being more similar than opposite-gender targets, but the magnitude of this categorization effect was stronger among men $\left(\eta_{\mathrm{p}}{ }^{2}=.32\right)$ than women $\left(\eta_{\mathrm{p}}^{2}=.15\right)$. Second, type of similarity interacted with social influence strategy, $F(1,167)=4.31, p<.04, \mathrm{\eta}_{\mathrm{p}}^{2}=.03$. As shown in the bottom of Table 1, participants in both social influence strategy conditions categorized targets according to gender, but the magnitude of this effect was greater in the weaknessfocused conditions $\left(\eta_{\mathrm{p}}^{2}=.34\right)$ than in the strength-focused conditions $\left(\eta_{\mathrm{p}}{ }^{2}=.15\right)$.

The predicted interaction between type of similarity judgment, participant gender, and social influence strategy was not significant $(F<1.5)$. However, the effects of participant gender and social influence strategy on categorization additively combined to produce the predicted pattern of effects. As the left side of Table 2 shows, there was significant categorization (same-gender $>$ opposite-gender similarity) among weakness-focused men $\left(\eta_{p}{ }^{2}=.46\right)$, strength-focused men $\left(\eta_{\mathrm{p}}^{2}=.20\right)$, and weakness-focused women $\left(\eta_{\mathrm{p}}{ }^{2}=.24\right)$ but not strength-focused women $\left(\eta_{\mathrm{p}}{ }^{2}=.06\right)$. The right side of Table 2 depicts the categorization effects in each condition. These means show that strength-focused men and weakness-focused women exhibited categorization effects of nearly identical magnitude (contrast coded $-1-1 ; F<.01$ ), which were of lesser magnitude than the categorization effects exhibited by weakness-focused men (contrast coded 2), $F(1,167)=3.71, p$ $<.056$.

\section{Female Position Assignment}

Female position assignment was submitted to a Social Influence Strategy $\times$ Participant Gender between-participants ANOVA. A main effect of participant gender, $F(1,167)=6.44$, $p<.02, \eta_{\mathrm{p}}^{2}=.04$, revealed that more valued positions were assigned to female subordinates by female participants $(M=4.69)$ than male participants $(M=4.10)$. The only other significant

${ }^{1}$ This coding assumes equal intervals, which may or may not be the case. Therefore, analyses were also performed using a basic distinction: potential to earn money (first-round player or captain) versus no potential to earn money (omitted from team or nonplaying alternate), which produced results parallel to those reported in the text. 
Table 2. Categorization as Measured by Paired Similarity in Each Condition of the Full Experimental Design, Experiment 1

\begin{tabular}{|c|c|c|c|c|c|c|}
\hline \multirow{3}{*}{$\begin{array}{l}\text { Participant } \\
\text { gender }\end{array}$} & \multicolumn{4}{|c|}{$\begin{array}{l}\text { Perceived similarity ratings: Same gender and } \\
\text { opposite gender targets }\end{array}$} & \multirow{2}{*}{\multicolumn{2}{|c|}{$\begin{array}{l}\text { Categorization index: } \\
\text { Same gender-opposite gender }\end{array}$}} \\
\hline & \multicolumn{2}{|c|}{ Weakness focused } & \multicolumn{2}{|c|}{ Strength focused } & & \\
\hline & SameG & OppositeG & SameG & $\overline{\text { OppositeG }}$ & Weakness focused & Strength focused \\
\hline Men & $4.70_{\mathrm{a}}$ & $3.97_{b}$ & $4.56_{a}$ & $4.19_{b}$ & .63 & .33 \\
\hline Women & $4.51_{\mathrm{a}}$ & $4.14_{\mathrm{b}}$ & $4.36_{a}$ & $4.18_{\mathrm{a}}$ & .33 & .13 \\
\hline
\end{tabular}

Note. In the left side of the table, (a) within social influence strategy conditions, adjacent means with different subscripts significantly differ at $p<.05$, and (b) within rows, different subscripts associated with a given variable (same gender or opposite gender) indicate significant differences across social influence strategy condition at $p<$ .05 . SameG $=$ same gender pairs of targets; OppositeG $=$ opposite gender pairs of targets.

effect to emerge from this analysis was the predicted Social Influence Strategy $\times$ Participant Gender interaction, $F(1,167)$ $=4.06, p<.05, \eta_{\mathrm{p}}^{2}=.03$. The means for this interaction are depicted in Table 3. To interpret this interaction, we performed simple effects tests that compared the responding of male versus female participants within levels of social influence strategy. These analyses revealed that in the weakness-focused conditions, female subordinates received fewer valued positions from male participants than female participants, $F(1,17)$ $=12.32, p<.01, \eta_{\mathrm{p}}^{2}=.07$. In contrast, there was no difference in the responding of male and female participants in the strengthfocused conditions $(F<1)$. We also estimated contrasts that compared the magnitude of social influence strategy effects within levels of gender. These analyses revealed that weakness-focused men assigned female subordinates fewer valued positions than did strength-focused men, $F(1,167)=4.53$, $p<.07, p_{\mathrm{a}=.05}<.035, \mathrm{\eta}_{\mathrm{p}}{ }^{2}=.03$, whereas strength-focused women and weakness-focused women did not differ $(F<1)$.

\section{Praise}

Female and male praise were submitted to a Social Influence Strategy $\times$ Participant Gender $\times$ Target Gender mixedmodel ANOVA. Because participants gave feedback to both male and female subordinates, target gender was a within-participants variable in this analysis. Social influence strategy and participant gender were between-participants variables.

The predicted Social Influence Strategy $\times$ Participant Gender $\times$ Target Gender interaction emerged on praise, $F(1,167)$ $=6.86, p<.01, \eta_{\mathrm{p}}^{2}=.06$. The means for this interaction are presented in the left side of Table 4 . To decompose this interaction, we first performed simple effects tests that examined the

Table 3. Female Position Assignment as a Function of Social Influence Strategy and Participant Gender, Experiment 1

\begin{tabular}{ccc}
\hline Participant gender & Weakness focused & Strength focused \\
\hline Men & $3.79 \mathrm{a}$ & $4.47_{\mathrm{b}}$ \\
Women & $4.76_{\mathrm{b}}$ & $4.58_{\mathrm{b}}$ \\
\hline
\end{tabular}

Note. Within rows and columns, means with different subscripts significantly differ at $p<.05$. The two italicized means reflect a significant comparison that became marginally significant when controlling for the number of comparisons $(p<.07)$. magnitude of gender bias within each condition. These analyses revealed significant gender bias in only one condition. Weakness-focused men praised female subordinates more than male subordinates, $F(1,38)=13.07, p<.01, \eta_{p}{ }^{2}=.26$. Participants in the other three conditions showed no evidence of gender biases in praise (all $F_{\mathrm{s}}<1, \eta_{\mathrm{p}}{ }^{2} \mathrm{~s}<.01$; see right side of Table 4). We also examined gender bias within social influence strategy condition and the magnitude of social influence strategy effects for male and female participants. The results of these analyses further show that the responses of weakness-focused men drove the interaction. Weakness-focused men exhibited stronger pro-female biases in praise than did either strength-focused men $\left(\eta_{\mathrm{p}}{ }^{2}=.08\right)$ or weakness-focused women $\left(\eta_{\mathrm{p}}^{2}=.07\right)$, both $F_{\mathrm{s}}(1,176)>9.75$, $p$ s <.01. There were no gender differences in praise within the strength-focused conditions, nor were there effects of social influence strategy among female participants (both $F_{s}<1$ ).

\section{Correlational Analyses}

To examine relations among variables, within conditions, we estimated correlations among categorization (see right side of Table 2) and both female position assignment and the bias index (see right side of Table 4). As shown in Table 5, in the weakness-focused male conditions, categorization was associated with less favorable position assignments to women but more praise of women. In the other three conditions, categorization was not reliably related to position assignment or praise.

\section{Discussion}

Findings across variables were consistent with predictions. Weakness-focused men more strongly categorized subordinates than did strength-focused men or women. It is interesting that this pattern emerged from the additive combination of the two main effects on categorization. Subordinates were more strongly categorized according to gender by male participants than female participants and by weakness-focused participants than by strength-focused participants. Although the Social Influence Strategy $\times$ Participant Gender interaction did not approach significance, the two main effects combined to result in elevated categorization tendencies among weak- 
Table 4. Praise of Subordinates as a Function of Social Influence Strategy, Participant Gender, and Subordinate Gender, Experiment 1

\begin{tabular}{|c|c|c|c|c|c|c|}
\hline \multirow[b]{3}{*}{$\begin{array}{l}\text { Participant } \\
\text { gender }\end{array}$} & \multicolumn{4}{|c|}{ Praise ratings: Female and male target subordinates } & \multirow{2}{*}{\multicolumn{2}{|c|}{$\begin{array}{l}\text { Praise index: Female } \\
\text { praise-male praise }\end{array}$}} \\
\hline & \multicolumn{2}{|c|}{ Weakness focused } & \multicolumn{2}{|c|}{ Strength focused } & & \\
\hline & $\begin{array}{l}\text { Female } \\
\text { targets }\end{array}$ & $\begin{array}{l}\text { Male } \\
\text { targets }\end{array}$ & $\begin{array}{l}\text { Female } \\
\text { targets }\end{array}$ & $\begin{array}{l}\text { Male } \\
\text { targets }\end{array}$ & $\begin{array}{c}\text { Weakness } \\
\text { focused }\end{array}$ & $\begin{array}{l}\text { Strength } \\
\text { focused }\end{array}$ \\
\hline Men & $4.42_{\mathrm{a}}$ & $3.70_{b}$ & $3.84_{b}$ & $3.93_{b}$ & .72 & .06 \\
\hline Women & $3.69_{b}$ & $3.63_{\mathrm{b}}$ & $3.62_{b}$ & $3.64^{\mathrm{b}}$ & -.09 & -.01 \\
\hline
\end{tabular}

Note. In the left side of the table, within social influence strategy conditions, adjacent means with different subscripts significantly differ at $p<.05$. Additionally, within rows, different subscripts associated with a given variable (same gender or opposite gender) indicate significant differences across social influence strategy condition at $p<.05$.

ness-focused men relative to participants in the other three conditions.

Weakness-focused men also stereotyped subordinate women more strongly than did strength-focused men or women. However, stereotyping did not take the form of a traditional unidirectional stereotyping effect. Instead, consistent with predictions, weakness-focused men assigned low-power women fewer valued positions than did strength-focused men or women but more strongly praised low-power women. Additionally, correlations between categorization and both female position assignment and praise were in the expected directions in the critical condition. Among weakness-focused men, categorization was associated with the assignment of fewer valued positions to women but more praise of those same women.

In sum, the findings of Experiment 1 show that powerful men who were weakness focused categorized subordinates more strongly according to gender and gave female subordinates fewer valued resources, but more praise, then they gave subordinate men. In Experiment 2, we turned attention to the question of how the patronizing behaviors of powerful and weakness-focused men affected their low-power recipients.

\section{Experiment 2}

As noted at the outset, patronizing behavior has a duplicitous and unfair nature that may be more readily apparent to the low-power individuals who are the recipients of those acts than the high-power people who behave in such ways (Glick \& Fiske, 2001; Jackman, 1994; Pratto \& Walker, 2001). Considering this suggestion, as well as findings showing that anger is the primary emotion that people experience in response to perceptions of injustice (e.g., Mikula et al., 1998), we predicted that those who are treated in patronizing ways would be angry (both men and women). Anger is an approach motivation, but anger-inspired action requires both the perception of an aversive (or unjust) situation and a belief that one can act to alter that situation (e.g., Harmon-Jones et al., 2003). In a stereotype-relevant achievement domain, this has performance implications. The anger that low-power people feel when they are patronized should inspire performance strivings if, but only if, effort is perceived as being linked to task success and the amelioration of the anger-inspiring (patronizing) situation. Because men and women differ in their general tenden- cies to exhibit anger-inspired action (e.g., Thomas, 1989) and have different expectations for success in masculine domains (see Meece et al., 1982), we reasoned that men and women may differentially perceive action potentials and exhibit different performances. More specifically, we predicted that low-power men who are patronized should perform better, whereas lowpower women who are patronized should perform worse.

To examine the above suggestions, we used the same experimental context, instructions, and cover story as in Experiment 1. Participants in Experiment 2, however, were all assigned to the low-power role of team member. Following the introduction of the experimental context and role assignment, participants reported their interests in the tasks, performance expectations, and motivation to earn money. Then participants received feedback (praise or no praise) and position assignments (valued or devalued) from a male leader, reported their emotions (including anger), and completed a performance measure.

\section{Method}

\section{Participants}

Two hundred forty-two Pennsylvania State undergraduates (92 men and 150 women) participated in the experiment in return for credit toward the research participation requirement of their introductory psychology course. Each participant was randomly assigned to one of four conditions created by crossing praise (praise or no praise)

Table 5. Correlations Among Categorization and Female Position and Praise, Experiment 1

\begin{tabular}{|c|c|c|c|c|}
\hline \multirow{3}{*}{$\begin{array}{l}\text { Participant } \\
\text { gender }\end{array}$} & \multicolumn{4}{|c|}{ Social influence strategy } \\
\hline & \multicolumn{2}{|c|}{ Weakness focused ${ }^{a}$} & \multicolumn{2}{|c|}{ Strength focused ${ }^{\mathrm{b}}$} \\
\hline & Position & Praise & Position & Praise \\
\hline Male & $-.32^{*}$ & $.41^{* *}$ & .22 & .11 \\
\hline Female & .19 & -.01 & .14 & .01 \\
\hline
\end{tabular}

Note. Higher numbers on position and praise are associated with more pro-female tendencies.

a Male participants, $n=39$; female participants, $n=55$. ${ }^{\mathrm{b}}$ Male participants, $n=32$; female participants, $n=48$.

${ }^{*} p<.05 .{ }^{* *} p<.01$. 
and position assignment (valued or devalued). Nine participants (4 women and $5 \mathrm{men}$ ) who were equivalently distributed across the four experimental conditions expressed suspicion during debriefing and were therefore omitted from the working data set. The responses of 2 additional participants ( 1 woman and 1 man) were removed from the data set because they had completed a previous experiment using the same paradigm and experimental instructions. After omitting the responses of these participants, the working data set was composed of data from 145 women and 86 men.

\section{Procedure}

The cover story and experimental context were the same as in Study 1. Following the introduction to the experimental context and a brief examination of the kinds of problems that would be completed (which was intended to increase apparent masculinity of the context), participants reported their interest in the experimental tasks and performance expectations as well as their motivation to earn money. This permitted an examination of the degree to which men and women differed in their interest in the masculine tasks and performance expectations. Participants then completed the leadership questionnaire, selected personal identifiers (i.e., gendered icon and user ID), and completed the two background questions to be shared with others on the team (i.e., described an academic strength in one sentence and an academic weakness in a second sentence). All participants were informed that another person in the session had been selected as the team leader and that they would complete the experiment as a low-power team member. The staged interaction then began, and participants received e-mails from the male leader, as indicated by a male icon and the user ID "JimmyJohn." The content of the e-mail message was altered to manipulate praise (praise or no praise) and position assignment (valued or devalued).

Praise. In the high-praise condition, participants read an initial email that stated,

Your answers to the getting acquainted questions were excellent. Your answers were also extremely informative. You were chosen for the team because it was believed that you would definitely make a contribution. You were also chosen for the team because it was believed that you would definitely be a supportive team member.

In contrast, in the low-praise conditions, participants initially read the following:

Your answers to the getting acquainted questions were average. Your answers were also slightly informative. You were chosen for the team because it was believed that you might make a contribution. You were also chosen for the team because it was believed that you might be a supportive team member.

Position assignment. As noted above, all participants were told that they were selected for the team, but their positions on the team varied. In the valued-position conditions, participants read that they had been selected for the team and assigned a first-round player position. In the devalued-position conditions, participants made the team but were then assigned a nonplaying alternate position. The differential value of these positions was clear given that participants previously read the written introduction to the experiment, which included information about the reward structure; valued positions had potential for rewards, whereas devalued positions did not.

Following the receipt of position assignment and praise but prior to the completion of the first set of problems, participants reported the extent to which they were currently experiencing eight feelings. These items were intended to tap anger as well as anxiety and confidence, which have also been suggested to have performance implications (e.g., Steele \& Aronson, 1995; Vescio et al., 2003). On completion of the feeling ratings, participants were presented with problems adapted from typical quantitative and logic Scholastic Achievement Test and
Graduate Record Examination problems; the contexts and appearance were altered to create the perception that completion of the problems required knowledge of stereotypically masculine domains (e.g., war games, sports problems). Each of the 11 problems was selected on the basis of the fact that it required attention and careful thought but was not excessively difficult. All participants completed the same problems and were given $10 \mathrm{~min}$ to complete the problems. At the end of the 10min interval, the problems window automatically closed.

To assure strong manipulations of position assignment and praise and to permit perceptions that participants could improve performance through effort, the critical round of activities was repeated. More specifically, participants waited for $1.5 \mathrm{~min}$ after completing the first 11 problems and then received a second e-mail. The second e-mail message was consistent with the first in terms of the manipulations (i.e., a participant received consistent praise and consistent position assignments across e-mail). However, the specific content of the e-mail message was altered for believability purposes. For example, praise in the second e-mail was presented with respect to participants' performance on the first round of problems. After receiving feedback and the position assignment for the second round, participants reported their current feelings and completed a second set of problems (this time there were 12 instead of 11).

When the problem window closed the second time, a message came across the screen, which read "Time's Up" and indicated that there was not enough time for another round of problems. Participants then completed an exit questionnaire and were fully debriefed.

\section{Dependent Variables}

Initial motivation. After the introduction to the masculine context but prior to the manipulation of praise and role assignment, participants completed four questions to assess the effects of the experimental context on motivation. These measures were included to assess the degree that masculine domains were threatening to women. Using a 9-point scale (endpoints not at all and extremely), participants reported their (a) interest in the experimental tasks ("In general, how interested are you in the strategic thinking, dynamic systems, and financial forecasting problems?"), (b) likely performance ("How well do you think you would perform on these tasks?"), (c) motivation to earn money ("How important is it to you to earn the highest possible monetary reward?"), and (d) perceived importance of the skills tapped ("How important are the general skills related to the challenge questions for getting ahead in life?").

Emotion: Anger, anxiety, and positive emotions. Immediately prior to the completion of the problems, participants reported the extent to which they were currently experiencing each of eight feelings. Using 9-point scales (endpoints not at all and extremely), participants reported the extent to which they were feeling anxious (reverse scored), confident, hopeful, jittery (reverse scored), angry (reverse scored), competent, optimistic, and mad (reverse scored). Responses to the eight affective ratings were submitted to principal-components factor analyses using a varimax rotation; analyses were performed separately for Time 1 and Time 2 reports. In both analyses, a three-factor solution emerged, as indicated by the scree plot and an eigenvalue of greater than 1 criterion. All item loadings were greater than.70, no items crossloaded, and the two analyses produced the same factor structure. We averaged across items that loaded on a given factor to create three variables. We created anger variables by averaging across ratings of angry and mad (Time 1: $\alpha=.88$; Time 2 : $\alpha=.92$ ). We created anxiety variables by averaging across anxious and jittery (Time $1: \alpha=.70$; Time 2: $\alpha=.71)$. We created positive emotion variables by averaging across confident, hopeful, competent, and optimistic (Time 1: $\alpha=.80$; Time 2: $\alpha=.90$ ). Higher numbers indicate stronger emotion (i.e., more anger, anxiety, and positive emotion).

Performance. Each correctly answered problem was assigned a score of 1 . Each unanswered or incorrectly answered problem received a value of zero. We summed across appropriate problems to create Time 1 and Time 2 performance scores. 


\section{Results}

Male and female participants in the patronizing (praise-devalued position) condition were expected to be angrier than participants in the other conditions. However, anger was expected to have different performance implications for men and women. In the patronizing (praise-devalued position) condition, men were expected to perform better, whereas women were expected to perform worse. To test these predictions, dependent variables (motivation, emotion, and performance) were submitted to a Position Assignment (valued or devalued) $\times$ Praise (praise or no praise) $\times$ Participant Gender (male or female) ANOVA. Between-participants ANOVAs were performed on the motivation items. Mixed-model ANOVAs (treating time of measurement as a within-participants factor) were performed on the emotion and performance variables. Significant interactions were further explored by means of simple effects tests and using Bonferroni corrections controlling for the familywise error rate.

\section{Initial Motivation}

Analyses performed on the motivation items revealed significant main effects of participant gender on interest, $F(1$, $212)=29.75, p<.0001, \eta_{\mathrm{p}}^{2}=.12$, and own performance estimates, $F(1,212)=22.69, p<.0001, \eta_{\mathrm{p}}{ }^{2}=.09$. Overall, women were less interested in the experimental problems $(M=4.69)$ and estimated lower personal performances on the problems $(M=5.29)$ than did men $(M s=6.23$ and 6.48 for interest and personal performance, respectively). No significant effects emerged on the motivation to earn money or the perceived importance of the masculine skills tapped for success in life (all Fs $<1)$.

\section{Emotion}

Anger. The analysis of anger produced three significant effects. First, there was a main effect of time, $F(1,212)=16.35, p$ $<.0001, \mathrm{\eta}_{\mathrm{p}}^{2}=.07$. Participants became angrier across time (Ms $=1.54$ and 2.10 for Times 1 and 2, respectively). Second, there was a main effect of position assignment, $F(1,212)=6.78, p$ $<.01, \mathrm{\eta}_{\mathrm{p}}^{2}=.03$. Participants were angrier when assigned devalued rather than valued positions, but this effect was qualified by a higher order interaction. Third, and consistent with predictions, the Praise $\times$ Position assignment was significant, $F(1,212)=4.89, p<.03, \eta_{p}^{2}=.02$. Simple effects tests revealed that participants in the praise conditions were angrier when assigned devalued positions $(M=3.15)$ than valued positions $(M=1.37), F(1,212)=9.67, p<.005, \eta_{p}^{2}=.04$. In contrast, in the no-praise conditions, participants anger did not vary as a function of position assignment $(M s=1.66$ and 1.75, valued and devalued; $F<1$ ). We also performed simple effects tests that examined the effect of praise within levels of position assignment. Findings from these analyses indicated that participants who were assigned devalued positions were angrier when they were praised $(M=3.15)$ versus not praised $(M$ $=1.75), F(1,212)=5.10, p<.05, \mathrm{n}_{\mathrm{p}}{ }^{2}=.02$. In the valued-position conditions, however, anger did not vary as a function of praise (praise $M=1.37$ and no-praise $M=1.66 ; F<1.3$ ).

Anxiety and positive emotion. Consistent with our suggestion that anger would be the primary emotion aroused by pa- tronizing acts, there was no evidence that praise and position assignment interactively influenced anxiety or positive emotion (both $F s<1$ ). In fact, analysis of positive emotion produced only two significant main effects. There were significant main effects of time, $F(1,212)=61.30, p<.0001, \eta_{p}{ }^{2}$ $=.22$, and participant gender, $F(1,212)=12.79, p<.0004, \eta_{\mathrm{p}}$ $=.06$, such that positive emotion decreased across time $(\mathrm{Ms}=$ 6.06 and 5.42 for Times 1 and 2, respectively) and was lower among women $(M=5.44)$ than men $(M=6.26)$. Analysis of anxiety produced a single significant effect: Time $\times$ Position Assignment, $F(1,212)=5.38, p<.022, \eta_{\mathrm{p}}{ }^{2}=.02$. To decompose this interaction, we performed simple effects tests that estimated the effect of time within levels of position assignment. Neither of these comparisons was significant $(F \mathrm{~s}<3.08, p \mathrm{~s}$ $>$.16; critical value $F=5.17$ ), but among participants in the valued-position conditions, there was a slight tendency for anxiety to increase from Time $1(M=2.83)$ to Time $2(M=$ $\left.3.05 ; \eta_{\mathrm{p}}{ }^{2}=.03\right)$, whereas the reverse was true for participants in the devalued position conditions (Time 1: $M=3.06$; Time 2: $M=2.83 ; \eta_{\mathrm{p}}{ }^{2}=.02$ ). We also examined the effect of position assignment within level of time; neither comparison was significant (both $F \mathrm{~s}<1, \eta_{\mathrm{p}}{ }^{2} \mathrm{~s}<.01$ ).

\section{Performance}

Analysis of performance revealed two significant main effects. A main effect of time, $F(1,212)=6.63, p<.02, \eta_{p}{ }^{2}=.03$, indicated that math scores were higher at Time $1(M=5.26)$ than Time $2(M=4.78)$. There was also a main effect of participant gender, $F(1,212)=4.52, p<.04, \eta_{\mathrm{p}}{ }^{2}=.02$; overall, women's math scores $(M=9.76)$ were lower than men's math scores $(M=10.54)$. However, a Position $\times$ Participant Gender interaction, $F(1,212)=4.59, p<.04, \eta_{\mathrm{p}}^{2}=.02$, further indicated that women $(M=9.51)$ performed more poorly than did men $(M$ $=11.09)$ in the devalued-position conditions, $F(1,212)=7.04$, $p<.01, \eta_{\mathrm{p}}{ }^{2}=.04$, but women $(M=10.12)$ and men $(M=10.05)$ performed similarly in the valued-position conditions $(F<1)$. Additionally, these effects were further qualified by the predicted Praise $\times$ Position Assignment $\times$ Participant Gender interaction, $F(1,212)=4.03, p<.05, \eta_{p}{ }^{2}=.02$. The means for this interaction are presented in Table 6 .

To decompose the three-way interaction, we first estimated contrasts that examined the Participant Gender $\times$ Position interaction within levels of praise. This interaction was significant in the praise conditions, $F(1,212)=7.10, p<.01, \eta_{\mathrm{p}}^{2}=.04$, but not the no-praise conditions $(F<1)$. In fact, in the nopraise conditions, none of the adjacent means differed (even when we did not control for the number of comparisons made; all $F_{\mathrm{S}}<1$ ).

Table 6. Performance as a Function of Role Assignment, Praise, and Participant Gender, Experiment 2

\begin{tabular}{lrrrcc}
\hline \multirow{2}{*}{$\begin{array}{l}\text { Position } \\
\text { assignment }\end{array}$} & \multicolumn{2}{c}{ Praise } & & \multicolumn{2}{c}{ No praise } \\
\cline { 2 - 3 } \cline { 5 - 6 } & Women & Men & & Women & Men \\
\hline Valued & $10.48_{\mathrm{a}}$ & $10.00_{\mathrm{a}}$ & & $9.699_{\mathrm{a}}$ & $10.19_{\mathrm{a}}$ \\
Devalued & $9.02_{\mathrm{b}}$ & $11.86_{\mathrm{c}}$ & & $9.99_{\mathrm{a}}$ & $10.50_{\mathrm{a}}$ \\
\hline
\end{tabular}

Note. Within praise conditions, adjacent means with different subscripts significantly differ at $p<.05$. 
To further decompose the significant Praise $\times$ Position Assignment interaction that emerged in the praise conditions, we focused on just the praise conditions and estimated contrasts that compared male and female performance within position assignment. These analyses revealed gender differences in performance in just one condition - the patronizing condition. In the patronizing (devalued position-high praise) condition, women performed more poorly than men, $F(1,212)=10.17, p$ $<.01, \eta_{\mathrm{p}}{ }^{2}=.05$. It is important to note that there were no reliable gender differences in the valued position-praise condition (all Fs $\left.<1, \eta_{\mathrm{p}}{ }^{2}>.01\right)$.

To examine the source of the gender difference in the patronizing (praise-devalued position) condition, we performed two final analyses. First, within the praise conditions, we performed simple effects tests that examined the effect of position assignment on performance within level of gender. These analyses indicated that women who were praised performed worse when assigned devalued positions (i.e., patronizing condition) than valued positions, whereas men who were praised performed better when assigned devalued positions than valued positions, both $F \mathrm{~s}(1,212)>4.24$, $p \mathrm{~s}<.04$, adjusted $p \mathrm{~s}_{\mathrm{a}=.025}<.09$, both $\eta_{\mathrm{p}}{ }^{2} \mathrm{~s}=.02$. Finally, we estimated contrasts that compared men's and women's performance in the patronizing (praise-devalued position) conditions (contrast coded -3) with the performance of same-gender participants in the other three conditions (each contrast coded +1 ). Both of these contrasts were significant, $F_{s}(1,212)>3.88, p s<.051$. Women's performance in the patronizing condition was worse than women's performance in the other conditions, but men's performance was better.

\section{Correlational Analyses}

Within conditions, we computed correlations between anger and performance. These variables were significantly related in only one condition - the patronizing (praise-devalued position) condition (all other conditions, rs <.19 for both men and women). Among male participants, anger and performance were strongly and positively correlated $(r=.62, p<.01$, $n=20$ ), consistent with the notion that anger is an approach emotion, and men perceived that they could act (increase effort) to ameliorate an anger-provoking situation. Among female participants, anger and performance were uncorrelated $(r=.04, n=34)$. As we discuss below, the latter finding is consistent with the findings of Harmon-Jones et al. (2003) and is what would be expected if anger persists but is unrelated to approach motivation when one perceives no actions that could ameliorate the anger-inspiring situation.

\section{Discussion}

Across dependent variables, findings were consistent and paint an interesting portrait of the effects of patronizing behavior. First, analyses of the motive variables suggest that men and women differentially perceived the stereotype relevance of the experimental context. Whereas men and women reported similar desires to earn monetary incentives and had similar perceptions of the degree that the masculine skills required in the experiment were important to getting ahead in life, men and women differed in their perceptions of how well they thought they would perform. Women reported less interest in the tasks than did men and estimated poorer personal performances. Given these findings, we would expect both men and women to feel angry when treated in patronizing ways but perhaps to interpret those behaviors differentially.

Consistent with this logic, analyses of anger produced a significant Position Assignment $\times$ Praise interaction, which was unqualified by higher order effects involving participant gender. Both male and female participants were angrier in the patronizing (devalued position-high praise) condition than in the other conditions. We also assessed anxiety and positive emotions, both of which have been suggested to have performance implications in stereotype-relevant domains (see Steele \& Aronson, 1995; Vescio et al., 2003). There were some effects on these variables. For instance, main effects of time and gender on positive emotions showed that people became less positive across time and that women were generally less positive than men (consistent with the motivation findings), but these positive emotions were not affected by the manipulation of position assignment or praise. Additionally, time interacted with position assignment to influence anxiety, but none of the individual cell means reliably differed.

Being the recipient of patronizing behaviors also had performance implications. Men performed better than women in the patronizing behavior condition. It is important to note that this was the only condition in which reliable gender differences in performance emerged. Consistent with predictions, men in the patronizing condition also performed better than men in the other conditions, whereas women displayed performance decrements. Correlational analyses also showed different patterns of relations among anger and performance among men and women in the patronizing condition. Among men, anger was positively associated with performance. Among women, anger was not associated with performance.

At first blush, one may wonder why there was not a significant negative correlation among anger and performance for women in the patronizing (devalued position-high praise) condition. However, our findings nicely replicate those of Harmon-Jones et al. (2003). When action potential existed in an anger-inducing situation, Harmon-Jones et al. found that self-reported anger was positively correlated with both left frontal cortical activity and action (i.e., signing a petition to try to rectify the situation). In contrast, when no action potential was available, participants were equally as angry as those in the action potential condition, but left cortical activity reduced to baseline. Additionally, anger was no longer associated with asymmetries in front cortical activity, consistent with the notion that anger persisted while participants remained in the situation. However, electroencephalogram measures of frontal cortical activity (associated with approach motivation) continued to predict action (or petition signing).

Extending the findings of Harmon-Jones et al. (2003) to the present research suggests that women in the patronizing condition may have failed to perceive that their performance strivings were related to task success and the amelioration of the anger-inspiring situation, such that anger persisted but was no longer associated with approach motivations. To the degree that anger and approach motivation become dissociated, anger would not be expected to be associated with performance, but approach motivation should. We cannot directly test this possibility because we did not measure approach motivation (e.g., relative left midfrontal cortical activity). Our findings are, however, completely consistent with this possibility. In fact, the pattern we would expect if this interpretation held would be a lack of correlation between anger and performance as op- 
posed to a significant negative correlation between anger and performance.

In sum, the findings of Experiment 2 are consistent with the two suggestions that motivated the study. First, consistent with predictions, anger was aroused among both male and female participants in the patronizing (praise-devalued position) condition relative to the other conditions. Second, gender differences in performance only emerged in the patronizing (devalued position-high praise) condition. Consistent with predictions, men performed better in the patronizing condition than the other conditions, whereas women performed worse.

\section{General Discussion}

The present research was motivated by the proposition that when powerful people stereotype their subordinates, they may behave in patronizing ways that have meaningful implications for the low-power recipients of those behaviors. To examine this possibility, we conducted two coordinated experiments that presented male and female participants with a masculine context (where attributes necessary for success were stereotypically associated with men). In Experiment 1, all participants were assigned high-power ("team leader") roles and assigned positions and provided feedback to male and female subordinates. Informed by the findings of Experiment 1 concerning the behaviors of the powerful, we then examined the effects of the behaviors of the powerful in Experiment 2; participants were assigned low-power ("team member") roles and received position assignments (valued or devalued) and praise (high or low) from a powerful male leader ("JimmyJohn") during apparent computer interactions.

The findings across the two experiments replicate and extend prior research in several important regards. First, replicating recent findings (Vescio et al., 2003), the findings of Experiment 1 reveal that powerful men stereotyped female subordinates only when the cultural stereotypes of women matched and informed the social influence strategy adopted by the powerful. In other words, weakness-focused men stereotyped their subordinates, whereas strength-focused men and women (whether strength or weakness focused) did not. Extending recent work (Vescio et al., 2003), Experiment 1 further revealed that the weakness-focused men did not exhibit a unidirectional antifemale bias. Instead, consistent with predictions, weakness-focused men gave their female subordinates few valued resources and much praise. Together, the findings of Experiment 1 point to the conditions that promote (and eliminate) the stereotyping tendencies of powerful men in masculine domains and the patronizing way that powerful men sometimes behave toward the female subordinates whom they stereotype.

Additionally, extending prior work, the findings of Experiment 2 attest to the meaningful consequences that the behaviors of the powerful have for their recipients. The findings of Experiment 2 indicate that low-power people (men and women) who are treated in patronizing ways are angrier than those who are not treated in patronizing ways (including those treated in consistently negative ways). Experiment 2 additionally documented that the effects that the patronizing behaviors of powerful people had on the performance of lowpower individuals varied as a function of participant gender. Significant gender differences in performance emerged only in the patronizing behavior condition - men performed better than women. Additionally, comparisons across conditions revealed that men performed better in the patronizing condition, whereas women performed worse.

Together, the findings across our two experiments suggest that the powerful do not always stereotype their subordinates, even in stereotype-relevant domains. However, when they do stereotype their subordinates, the stereotyping tendencies of the powerful may result in duplicitous behaviors toward lowpower people, which can have meaningful implications for the recipients of those behaviors. Low-power people who are stereotyped may (a) receive few valued resources but much praise; (b) experience anger; and (c) either perform better or worse, depending on the degree that they perceive that their actions can (or cannot) ameliorate the anger-inspiring situation. These findings raise several important questions and considerations for future theorizing and research on stereotyping and prejudice.

\section{Patronizing Environments and Emotional Arousal: Anger Versus Hope}

We reasoned that being the recipient of the patronizing behaviors of powerful others may be anger inspiring. Additionally, because anger is an approach motivation, we wondered whether there may be performance implications, which vary as a function of gender differences in perceived action potential (Harmon-Jones et al., 2003). Our findings were consistent with this suggestion. However, hope is also an approach motivation that might have similar performance implications. That is, perceiving the potential to act in ways that could ameliorate a patronizing and anger-inspiring situation may arouse hope and inspire action. In contrast, the failure to perceive actions that could alter a patronizing situation may leave one feeling hopeless and lead to reduced action.

We did not find strong evidence consistent with the hope interpretation of the data from Experiment 2. However, we also cannot definitely rule out such a possibility. When we analyzed hope and optimism separately from the positive emotion index created in Experiment 2, the only reliable effect to emerge on each rating were main effects of participant gender-women were less hopeful and less confident than were men. It is interesting, however, that the one other effect that approached significance in these two analyses was the threeway interaction between participant gender, position assignment, and praise on hope ( $p$ s <.14), which resulted from the fact that women in the patronizing conditions were less hopeful than women in other conditions (though men in these conditions were not more hopeful). This raises the possibility that measures of hope that are based on multiple items versus a single item may point to effects we failed to detect, and future research may benefit from examining multiple approach motivations.

Findings that hope as well as anger is related to the performance of low-power individuals in stereotype-relevant domains would further highlight the importance of examining approach motivations and their performance implications. At present, there is a sizable body of evidence showing that members of stereotyped groups often underperform in stereotyperelevant domains. However, evidence of mechanisms that produce such effects has been relatively less abundant (see Wheeler \& Petty, 2001), which may be due partly to the pri- 
mary focus on inhibition-related emotions and cognitive factors. The present findings suggest that emotions associated with the approach system may also influence the performance of members of negatively stereotyped groups in stereotyperelevant domains.

\section{Anger Arousal, Approach Motivation, and the Perceptions of Action Potential}

The present research has also documented positive outcomes associated with anger arousal. Although these outcomes differed for low-power men and women in the current experimental context (e.g., men performed better and women performed worse), they also raise the possibility that anger (as opposed to anxiety, dejection, or stress) among members of negatively stereotyped groups could produce increased effort and enhanced performance. In the present experimental context, low-power individuals were completely dependent on powerful others, such that it may have been hard to conceive of actions that would ameliorate the situation for members of negatively stereotyped groups. However, situations that provide low-power people with action potential (e.g., avenues to submit complaints about superiors that are taken seriously) might have very different effects, such that anger inspires action (and possibly hope) as well as persistence. This implies that situational factors are important in (a) determining how the powerful behave, (b) providing information about the acceptable and unacceptable behaviors of the powerful, and (c) providing low-power people with information about available actions should one find that they are confronted with an anger-inspiring situation.

\section{The Stereotyping of the Powerful and Patronizing Behaviors}

Given the predictions of the Social Influence Strategy $\times$ Stereotype Match model (Vescio et al., 2003), we would expect the patronizing behaviors of powerful people to follow from stereotype-based judgments and only occur in conditions where the cultural stereotypes of the groups to which low-power people belong match the social influence strategies adopted by the powerful. We would not, however, expect patronizing behaviors to occur in all situations where social influence strategies and stereotypes match. This is because the "wow" response that motivates the praise of stereotyped group members derives from violations of low stereotype-based expectations. If a group is positively stereotyped (such as Asian Americans in math or technical contexts), high performance should be expected, and expectancy violations should be less frequent. Thus, we suspect that patronizing behaviors are bestowed only on those individuals who belong to negatively stereotyped groups (e.g., women and African Americans).

\section{Concluding Comments}

According to Merriam-Webster's Collegiate Dictionary (1993), to patronize means (a) to act as a patron of; provide aid or support of; or (b) to adopt an air of condescension toward. This definition is interesting in light of the foundational assumption and novel suggestion from which the Social Influence Strategy $\times$ Stereotype Match model derived. Vescio et al. (2003) assumed that powerful people are motivated to fairly and effectively influence their subordinates as they strive to- ward a common goal. From this perspective, stereotyping occurs when it slips by undetected, when stereotypes match the social influence strategies adopted by the powerful. Extending these suggestions, and considering the definition of patronize, the present theorizing and findings introduce the possibility that powerful people sincerely adopt a patron status toward their subordinates, believing that they are aiding and supporting their subordinates. Although the motivation may be genuine, one may adopt an air of condescension toward one's subordinates when stereotyping unwittingly occurs. These suggestions are consistent with prior theorizing on paternalistic relations (e.g., Jackman, 1994; Pratto \& Walker, 2001) but imply different underlying motivations and different ways of ameliorating the patronizing acts of the powerful. Encouragingly, whereas many traditional achievement domains encourage leadership styles that rely on weakness-focused social influence strategies, our findings suggest that a restructuring of situational norms and goal statements given considerations of how subordinates may promote (rather than thwart) goal strivings may minimize the influence of stereotypes and eradicate both the patronizing behaviors of the powerful and the consequential underperformance of low-power individuals who belong to negatively stereotyped groups.

\section{References}

Allport, G. W. (1954). The nature of prejudice. Cambridge, MA: Perseus Books.

Biernat, M., \& Vescio, T. K. (2002). She swings, she hits, she's great, she's benched: Shifting judgment standards and behavior. Personality and Social Psychology Bulletin, 28, 66-76.

Biernat, M., Vescio, T. K., \& Manis, M. (1998). Judging and behaving toward members of stereotyped groups: A shifting standards perspective. In C.Sedikides, J.Schopler, \& C. A.Insko (Eds.), Intergroup cognition and intergroup behavior (pp. 151-175). Hillsdale, NJ: Erlbaum.

Brewer, M. B. (1988). A dual process model of impression formation. In T. K.Srull \& R. S.WyerJr. (Eds.), Advances in social cognition (Vol. 1, (pp. 1-36). Hillsdale, NJ: Erlbaum.

Bullock, S. C., \& Houston, E. (1987). Perceptions of racism by Black medical students attending White medical schools. Journal of the National Medical Association, 79, 601-608.

Cacioppo, J. T., \& Bernston, G. G. (1994). Relationship between attitudes and evaluative space: A critical review, with emphasis on the separability of positive and negative substrates. Psychological Bulletin, 115, 401-423.

Clayton, S. D. (1992). The experience of injustice: Some characteristics and correlates. Social Justice Research, 5, 71-91.

Coan, J., Allen, J. J. B., \& Harmon-Jones, E. (2001). Voluntary facial expression and hemispheric asymmetry over the frontal cortex. Psychophysiology, 38, 912-925.

Davidson, R. J. (1998). Anterior electrophysiological asymmetries, emotion, and depression: Conceptual and methodological conundrums. Psychophysiology, 35, 607-614.

Depue, R. A., \& Iacono, W. G. (1989). Neurobehavioral aspects of affective disorders. Annual Review of Psychology, 40, 457-492.

Diekman, A. B., \& Eagly, A. H. (2000). Stereotypes as dynamic constructs: Women and men of the past, present, and future. Personality and Social Psychology Bulletin, 26, 1171-1188.

Dovidio, J. F., Gaertner, S. L., Kawakami, K., \& Hodson, G. (2002) Why can't we just get along? Interpersonal biases and interracial distrust. Cultural Diversity and Ethnic Minority Research, 8, 88-102. 
Dovidio, J. F., Kawakami, K., \& Gaertner, S. L. (2002). Implicit and explicit prejudice and interracial interaction. Journal of Personality and Social Psychology, 82, 62-68.

Eagly, A., \& Karau, S. J. (2002). Role congruity theory of prejudice toward female leaders. Psychological Review, 109, 573-598.

Eagly, A., \& Mladinic, A. (1989). Gender stereotypes and attitudes toward women and men. Personality and Social Psychology Bulletin, 15, 543-558.

Fischer, A. H., Rodriguez Mosquera, P. M., van Vianen, A. E. M., \& Manstead, A. S. R. (2004). Gender and culture differences in emotion. Emotion, 4, 87-94.

Fiske, S. T. (1993). Controlling other people: The impact of power on stereotyping. American Psychologist, 48, 621-628.

Fiske, S. T. (2001). Effects of power on bias: Power explains and maintains individual, group, and societal disparities. In A. Y.Lee-Chai \& J. A.Bargh (Eds.), The use and abuse of power: Multiple perspectives on the causes of corruption (pp. 181-194). Philadelphia: Academic Press.

Fiske, S. T., Cuddy, A. J. C., Glick, P., \& Xu, J. (2002). A model of (often mixed) stereotype content: Competence and warmth respectively follow from perceived status and competition. Journal of Personality and Social Psychology, 82, 878-902.

Fiske, S. T., \& Neuberg, S. L. (1990). A continuum of impression formation, from category-based to individuating processes: Influences of information and motivation on attention and interpretation. In M.Zanna (Ed.), Advances in experimental social psychology (Vol. 23, (pp. 1-74). New York: Academic Press.

Fitness, J. (2000). Anger in the workplace: An emotion script approach to anger episodes between workers and their superiors, coworkers, and subordinates. Journal of Organizational Behavior, 21, 147-162.

Foschi, M. (1992). Gender and double standards for competence. In C. L.Ridgeway (Ed.), Gender, interaction, and inequality (pp. 181-207). New York: Springer-Verlag.

Frodi, A. (1978). Experiential and physiological responses associated with anger and aggression in women and men. Journal of Research in Personality, 12, 335-349.

Gaertner, S. L., \& Dovidio, J. F. (1986). The aversive form of racism. In J. F.Dovidio \& S. L.Gaertner (Eds.), Prejudice, discrimination, and racism (pp. 61-90). Orlando, FL: Academic Press.

Glick, P., \& Fiske, S. T. (1996). The ambivalent sexism inventory: Differentiating hostile and benevolent sexism. Journal of Personality and Social Psychology, 70, 491-512.

Glick, P., \& Fiske, S. T. (2001). An ambivalent alliance: Hostile and benevolent sexism as complementary justifications for gender inequality. American Psychologist, 56, 109-118.

Gray, J. A. (1982). The neuropsychology of anxiety: An inquiry into the functions of the septo-hippocampal system. New York: Oxford University Press.

Gray, J. A. (1987). The psychology of fear and stress. Cambridge, England: Cambridge University Press.

Harmon-Jones, E., \& Sigelman, J. (2001). State anger and prefrontal brain activity: Evidence that insult-related left-prefrontal activation is associated with experienced anger and aggression. Journal of Personality and Social Psychology, 80, 797-803.

Harmon-Jones, E., Sigelman, J. D., Bohlig, A., \& Harmon-Jones, C. (2003). Anger, coping, and frontal cortical activity: The effect of coping potential on anger-induced left frontal activity. Cognition and Emotion, 17, 1-24.

Hassenbrauck, M. (1986). Ratings of distress as a function of degree and kind of inequity. Journal of Social Psychology, 126, 269-270.

Jackman, M. R. (1994). The velvet glove: Paternalism and conflict in gender, class, and race relations. Berkeley: University of California Press.

Jost, J. T., \& Banaji, M. R. (1994). The role of stereotyping in system-justification and the production of a false consciousness. British Journal of Social Psychology, 33, 1-27.
Jussim, L., Coleman, L. M., \& Lerch, L. (1987). The nature of stereotypes: A comparison and integration of three theories. Journal of Personality and Social Psychology, 52, 536-546.

Keltner, C., Gruenfeld, D. H., \& Anderson, C. (2003). Power, approach, and inhibition. Psychological Review, 110, 265-284.

Kopper, B. A., \& Epperson, D. L. (1991). Women and anger: Sex and sex-role comparisons in the expression of anger. Psychology of Women Quarterly, 15, 7-14.

Kopper, B. A., \& Epperson, D. L. (1996). The experience and expression of anger: Relationships with gender, gender role socialization, depression, and mental health functioning. Journal of Counseling Psychology, 43, 158-165.

Lepore, L., \& Brown, R. (1997). Category and stereotype activation: Is prejudice inevitable?Journal of Personality and Social Psychology, 72, 275-287.

Maxwell, S. E., \& Delaney, H. D. (1990). Designing experiments and analyzing data: A model comparison perspective. Belmont, CA: Wadsworth.

Meece, J. L., Parsons, J. E., Kaczala, C. M., \& Goff, S. B. (1982). Sex differences in math achievement: Toward a model of academic choice. Psychological Bulletin, 91, 324-348.

Merriam-Webster's collegiate dictionary. (10th ed.) (1993). Springfield, MA: Merriam-Webster.

Mikula, G. (1986). The experience of injustice: Toward a better understanding of its phenomenology. In W. W.Bierhoff, R. L.Cohen, \& J.Greenberg (Eds.), Justice in social relations (pp. 223-244). New York: Plenum Press.

Mikula, G., Scherer, K. R., \& Athenstaedt, U. (1998). The role of injustice in the elicitation of differential emotional reactions. Personality and Social Psychology Bulletin, 24, 769-783.

Miller, D. T. (2001). Disrespect and the experience of injustice. Annual Review of Psychology, 52, 527-553.

Park, B., \& Judd, C. M. (1990). Measures and models of perceived variability. Journal of Personality and Social Psychology, 59, 173-191.

Parsons, J. E., Kaczala, C. M., \& Meece, J. L. (1982). Socialization of achievement attitudes and beliefs: Classroom influences. Child Development, 53, 322-339.

Plant, E. A., \& Devine, P. G. (1998). Internal and external motivation to respond without prejudice. Journal of Personality and Social Psychology, 75, 811-832.

Pratto, F., Sidanius, J., Stallworth, L. M., \& Malle, B. F. (1994). Social dominance orientation: A personality variable predicting social and political attitudes. Journal of Personality and Social Psychology, 67, 741-763.

Pratto, F., \& Walker, A. (2001). Dominance in disguise: Power, beneficence, and exploitation in personal relationships. In A. Y.Lee-Chai \& J. A.Bargh (Eds.), The use and abuse of power: Multiple perspectives on the causes of corruption (pp. 93-114). Philadelphia: Academic Press.

Rudman, L. A., \& Glick, P. (1999). Feminized management and backlash toward agentic women: The hidden costs to women of a kinder, gentler image of middle managers. Journal of Personality and Social Psychology, 77, 1004-1010.

Rudman, L. A., \& Glick, P. (2001). Prescriptive gender stereotypes and backlash toward agentic women. Journal of Social Issues, 57, 743-762.

Ryckman, D. B., \& Peckham, P. (1987). Gender differences in attributions for success and failure situations across subject areas. Journal of Educational Research, 81, 120-125.

Schmader, T., Major, B., \& Gramzow, R. H. (2001). Coping with ethnic stereotypes in the academic domain: Perceived injustice and psychological disengagement. Journal of Social Issues, 57, 93-111.

Shields, S. A. (2002). Speaking from the heart: Gender and the social meaning of emotion. Cambridge, England: Cambridge University Press.

Snyder, M., \& Miene, P. K. (1994). On the functions of stereotypes and prejudice. In M. P.Zanna (Ed.), The psychology of prejudice: The Ontario Symposium (Vol. 7, (pp. 33-54). Hillsdale, NJ: Erlbaum. 
Spence, J. T., \& Buckner, C. B. (2000). Instrumental and expressive traits, trait stereotypes, and sexist attitudes. Psychology of Women Quarterly, 24, 44-62.

Steele, C. M., \& Aronson, J. (1995). Stereotype threat and the intellectual test performance of African Americans. Journal of Personality and Social Psychology, 69, 797-811.

Steffen, P. R., McNeilly, M., Anderson, N., \& Sherwood, A. (2003). Effects of perceived racism and anger inhibition on ambulatory blood pressure in African Americans. Psychosomatic Medicine, 65, 746-750.

Stein, N. L., \& Levine, L. J. (1990). Making sense out of emotion: The representation and use of goal-structured knowledge. In N. L.Stein \& B.Leventhal (Eds.), Psychological and biological approaches to emotion (pp. 45-73). Hillsdale, NJ: Erlbaum.

Stipek, D. J. (1984). Sex differences in children's attributions for success and failure on math and spelling tests. Sex Roles, 11, 969-981.

Stroessner, S. J. (1996). Social categorization by race or sex: Effects of perceived non-normalcy on response times. Social Cognition, 14, 247-276.

Swim, J. K., Hyers, L. L., Cohen, L. L., \& Ferguson, M. J. (2001). Everyday sexism: Evidence for its incidence, nature, and psychological impact from three daily diary studies. Journal of Social Issues, $57,31-53$.

Swim, J. K., Hyers, L. L., Cohen, L. L., Fitzgerald, D. C., \& Bylsma, W. H. (2003). African American college students' experiences with everyday racism: Characteristics of and responses to these incidents. Journal of Black Psychology, 29, 38-67.

Tajfel, H. (1959). Quantitative judgment in social perception. British Journal of Psychology, 50, 16-29.
Thomas, S. P. (1989). Gender differences in anger expression: Health implications. Research in Nursing and Health, 12, 389-398.

Vescio, T. K., \& Biernat, M. (1999). When stereotype-based expectations impair perceivers' performance: The effect of prejudice, race, and target quality on judgments and perceiver performance. European Journal of Social Psychology, 29, 961-969.

Vescio, T. K., Gervais, S. J., \& Woodward, H. A. (2005). The positive selfstereotyping of male and female leaders in masculine domains: Different antecedents, but similar consequences.Manuscript under review.

Vescio, T. K., Heidenreich, S., \& Snyder, M. (2005). The effects of prejudice level and social influence strategy on stereotypic responding to racial outgroups.Manuscript submitted for publication.

Vescio, T. K., Snyder, M., \& Butz, D. A. (2003). Power in stereotypically masculine domains: A Social Influence Strategy $\times$ Stereotype Match model. Journal of Personality and Social Psychology, 85, 1062-1078.

Vorauer, J. D., \& Kumhyr, S. M. (2001). Is this about you or me? Selfversus other-directed judgments and feelings in response to in tergroup interactions. Personality and Social Psychology Bulletin, 27, 706-719.

Wheeler, S. C., \& Petty, R. E. (2001). The effects of stereotype activation on behavior: A review of possible mechanisms. Psychological Bulletin, 127, 797-826.

Wittenbrink, B., Gist, P. L., \& Hilton, J. L. (1997). Structural properties of stereotypic knowledge and their influences on the construal of social situations. Journal of Personality and Social Psychology, 72, 526-543.

Zarate, M. A., \& Smith, E. R. (1990). Person categorization and stereotyping. Social Cognition, 8, 161-185. 